\title{
The effect of exposure to biomass smoke on respiratory symptoms in adult rural and urban Nepalese populations
}

\author{
Om P Kurmi ${ }^{1}$, Sean Semple ${ }^{2}$, Graham S Devereux ${ }^{3}$, Santosh Gaihre ${ }^{2}$, Kin Bong Hubert Lam ${ }^{4}$, Steven Sadhra ${ }^{4}$, \\ Markus FC Steiner ${ }^{2}$, Padam Simkhada ${ }^{5}$, William CS Smith ${ }^{6}$ and Jon G Ayres ${ }^{4}$
}

\begin{abstract}
Background: Half of the world's population is exposed to household air pollution from biomass burning. This study aimed to assess the relationship between respiratory symptoms and biomass smoke exposure in rural and urban Nepal.

Methods: A cross-sectional study of adults $(16+$ years) in a rural population $(n=846)$ exposed to biomass smoke and a non-exposed urban population $(n=802)$ in Nepal. A validated questionnaire was used along with measures of indoor air quality ( $\mathrm{PM}_{2.5}$ and $\left.\mathrm{CO}\right)$ and outdoor $\mathrm{PM}_{2.5}$.

Results: Both men and women exposed to biomass smoke reported more respiratory symptoms compared to those exposed to clean fuel. Women exposed to biomass were more likely to complain of ever wheeze (32.0 \% vs. 23.5\%; $p=0.004)$ and breathlessness ( $17.8 \%$ vs. $12.0 \%, p=0.017)$ compared to males with tobacco smoking being a major risk factor. Chronic cough was similar in both the biomass and non-biomass smoke exposed groups whereas chronic phlegm was reported less frequently by participants exposed to biomass smoke. Higher PM $_{2.5}$ levels ( $\geq 2$ SDs of the 24-hour mean) were associated with breathlessness $(\mathrm{OR}=2.10,95 \% \mathrm{Cl} 1.47,2.99)$ and wheeze $(1.76,1.37,2.26)$.

Conclusions: The study suggests that while those exposed to biomass smoke had higher prevalence of respiratory symptoms, urban dwellers (who were exposed to higher ambient air pollution) were more at risk of having productive cough.
\end{abstract}

Keywords: Respiratory symptoms, Breathlessness, Phlegm, Solid fuel, Household air pollution

\section{Introduction}

While the major cause of respiratory health problems among adults in the developed world is smoking, exposure to particles generated from biomass smoke is a major cause of respiratory diseases in low income countries [1,2].

Several studies have reported higher prevalence of respiratory ill-health among adults exposed to biomass smoke with estimated risk ratios between 1.2 and 7.9 [3]. Most studies showing an association between household air pollution and respiratory health problems used proxy measurements of exposure such as the number of hours spent on cooking, or simply ever used particular fuels. In

\footnotetext{
* Correspondence: k.lam@bham.ac.uk

${ }^{4}$ Institute of Occupational and Environmental Medicine, University of Birmingham, Birmingham B15 2TT, UK

Full list of author information is available at the end of the article
}

addition, not all of the important confounders, particularly socio-economic status, smoking, fuel types and age, have been adjusted for in earlier studies. Although positive associations between chronic bronchitis and household air pollution have been reported, there were large variations in the prevalence of different respiratory symptoms $[4,5]$. A meta-analysis [3] reported positive associations between the use of solid fuels and both chronic obstructive pulmonary disease (COPD) $(\mathrm{OR}=2.80,95 \% \mathrm{CI} 1.85,4.00)$ and chronic bronchitis $(\mathrm{OR}=2.32,95 \% \mathrm{CI} 1.92,2.80)$ but also highlighted considerable heterogeneity in design, measurement, and sizes of effect estimates in studies from different low and middle income countries. To date, only one study from Nepal has reported a relationship between directly measured household exposure and respiratory symptoms 
although the exposure assessment was carried out only during cooking [6].

This study aimed to investigate the relationship between respiratory symptoms and lung function and direct measures of exposure to emissions from biomass and nonbiomass (particularly liquefied petroleum gas [LPG]) fuels in rural and urban households in Nepal. We previously reported a $20 \%$ prevalence of COPD in the biomass exposed population compared to $11 \%$ in the urban population based on spirometry data [7]. In this report we focus on the respiratory symptoms.

\section{Methods}

\section{Design and study sample}

This cross-sectional study was carried out between April 2006 and February 2007. The biomass-exposed population (98.9\% used wood) was sampled from two village development committees (VDCs) in the Kathmandu Valley. Four wards (out of nine) in each VDC were randomly selected and all individuals in the selected wards aged $\geq 16$ years were eligible if they met the inclusion criteria (no doctor diagnosed major respiratory or cardiovascular health problems and agreement to 24-h continuous airborne exposure monitoring in their homes). The non-exposed population (98.4\% used LPG) were selected from six wards (from a total of 35) in the Kathmandu municipality: three were selected randomly near the ring road and the other three selected from $1-2 \mathrm{~km}$ inside the ring road. Further details were published elsewhere $[7,8]$. The sample size was based on lung function assuming a prevalence of COPD of $10 \%$ in the non-exposed and $20 \%$ in the exposed populations, the latter being twice the reported prevalence for Nepalese populations [7].

An interviewer-administered questionnaire was used to collect data on smoking, socio-economic status, literacy, kitchen characteristics, cooking details, history of fuel use, and respiratory symptoms. The questionnaire was translated into Nepalese and back translated into English by an independent translator and a pilot study was conducted to identify issues of logistics and understanding. The study protocol was approved by the Nepal Health Research Council. Written, informed consent was obtained from all study participants.

\section{Measurements of exposure}

Levels of particulate matter with an aerodynamic diameter $<2.5 \mu \mathrm{m}\left(\mathrm{PM}_{2.5}\right)$ were measured over a continuous 24-h period in most dwellings $(n=490)$ using photometric devices (SidePak AM510 and DustTrak Model 8520, TSI Inc., Shoreview, MN, USA), from which mean 24-h $\mathrm{PM}_{2.5}$ (in $\mu \mathrm{g} / \mathrm{m}^{3}$ ) was derived. We report here the results from 442 households (206 biomass burning; 236 non-biomass burning) which had at least $20 \mathrm{~h}$ data. Outdoor $\mathrm{PM}_{2.5}$ concentrations were measured in both rural and urban areas on the veranda (for logistic and security reasons) in 118 homes (46 biomass burning, 72 nonbiomass burning). Indoor $24-\mathrm{h}$ carbon monoxide (CO) concentrations (in ppm) were measured in 126 homes (40 biomass burning, 86 non-biomass burning) using $\mathrm{HOBO}$ CO loggers (MicroDAQ, Contoocook, NH, USA). The direct reading photometric instruments were calibrated using data from co-located gravimetric samplers [8].

\section{Assessment of respiratory outcomes}

Respiratory symptoms were based on the Medical Research Council (MRC) questionnaire and included cough, phlegm, breathlessness, and wheezing/whistling. Breathlessness was measured using the five-level modified MRC (mMRC) dyspnoea scale [9]. In this report we define breathlessness as those falling into Grade 2 or above. Participants who reported to have cough or bring up phlegm first thing in the morning for at least three months each year were considered to have chronic cough or phlegm, respectively. Chronic bronchitis was defined as the presence of both chronic cough and chronic phlegm. Participants also underwent spirometry as reported elsewhere [9]. For comparability with previous studies, we defined airflow obstruction in two ways: (i) forced expiratory volume in $1 \mathrm{~s}\left(\mathrm{FEV}_{1}\right)$ to forced vital capacity (FVC) ratio less than the lower limit of normal (LLN); or (ii) $\mathrm{FEV}_{1} / \mathrm{FVC}<0.70$ [7].

\section{Covariates}

Height and weight were measured using standard protocols [10], from which body mass index (BMI) was computed (in $\mathrm{kg} / \mathrm{m}^{2}$ ). Participants were classified as non-, exand current smokers, where the latter two categories had smoked at least 20 packs of cigarettes or $360 \mathrm{~g}$ of tobacco in a lifetime, or at least one cigarette per day or one cigar a week for one year. We also collected information on exposure to environmental tobacco smoke and current occupation. We used monthly household income (in Nepalese Rupees where 1 US $\$ \approx 100$ Rs) and educational level as proxies for socio-economic status.

\section{Statistical analysis}

Statistical analyses were performed using STATA (version 12, College Station, TX, USA). Results for $\mathrm{PM}_{2.5}$ and $\mathrm{CO}$ concentrations are expressed as geometric means and geometric standard deviations unless indicated otherwise. Mean indoor $\mathrm{PM}_{2.5}$ concentrations $>2$ standard deviations (SD) of the arithmetic means over the entire sampling window were also calculated from the real time exposure data and are reported here to assess any associations between dependent variables and maximal exposures (i.e. during cooking). Baseline demographic characteristics were compared between biomass and non-biomass exposed participants separately for men and women by regression taking into account the household clustering effect. Regression 
models were constructed to evaluate the effect of pollutants (biomass, exposure to $\mathrm{PM}_{2.5}$ and $\mathrm{CO}$ independently) on respiratory symptoms. All known and potential confounders (age, income, educational level, smoking status, and BMI) were adjusted for to obtain regression coefficients $(\beta)$ with robust variance estimates to allow for household clustering.

\section{Results}

Among 1648 participants (762 men and 886 women) enrolled, 846 (51\%) used biomass and 802 (49\%) used nonbiomass fuels (primarily LPG), respectively. The proportion of current smokers, underweight, illiterate and those having lower income were higher among biomass users (Table 1). Around 35\% of rural women had smoked at some point in their lives compared to only $9 \%$ of urban dwellers.
The geometric mean ( \pm geometric SD) 24-h indoor $\mathrm{PM}_{2.5}$ concentration in biomass using homes was significantly greater than in non-biomass using homes $(455 \pm 2.4$ vs. $101 \pm 2.0 \mu \mathrm{g} / \mathrm{m}^{3}, \mathrm{p}<0.001$ ), although there was no significant difference in outdoor air pollution between biomass and non-biomass using homes $\left(129 \pm 2.7\right.$ vs. $115 \pm 2.5 \mu \mathrm{g} / \mathrm{m}^{3}$, $\mathrm{p}=0.249) . \mathrm{PM}_{2.5}$ measured concurrently on the veranda and $100 \mathrm{~m}$ from five biomass burning houses showed substantially higher concentrations $\left(129 \pm 1.5 \mu \mathrm{g} / \mathrm{m}^{3}\right)$ compared to the outdoor environment $\left(7.4 \pm 2.8 \mu \mathrm{g} / \mathrm{m}^{3}\right)$. Mean peak indoor $\mathrm{PM}_{2.5}$ (defined as $>2 \mathrm{SD}$ of the mean level over the entire sampling window) was $1790 \mu \mathrm{g} / \mathrm{m}^{3}$ in homes using biomass and $141 \mu \mathrm{g} / \mathrm{m}^{3}$ in non-biomass homes (arithmetic means 2828 and $335 \mu \mathrm{g} / \mathrm{m}^{3}$, respectively).

The 24-h CO concentrations in kitchens using biomass fuel were significantly higher than in non-biomass fuel

Table 1 Demographic data of 1648 Nepalese adult men and women according to household fuel type

\begin{tabular}{|c|c|c|c|c|c|c|}
\hline \multirow[b]{3}{*}{$\mathrm{n}$} & \multicolumn{3}{|c|}{ Men } & \multicolumn{3}{|c|}{ Women } \\
\hline & Biomass & Non-biomass & $\mathrm{p}$ & Biomass & Non-biomass & $\mathrm{p}$ \\
\hline & 382 & 380 & & 463 & 423 & \\
\hline Age (years); mean (SD) & $35.7(17.1)$ & $35.2(15.1)$ & 0.612 & $36.1(17.1)$ & $34.5(15.1)$ & 0.076 \\
\hline Height (cm); mean (SD) & $162.3(7.4)$ & $166.1(6.8)$ & $<0.001$ & $149.8(5.8)$ & $153.0(6.2)$ & $<0.001$ \\
\hline Weight (kg); mean (SD) & $52.6(8.2)$ & $61.9(10.2)$ & $<0.001$ & $46.2(7.2)$ & $56.0(10.3)$ & $<0.001$ \\
\hline \multicolumn{7}{|l|}{ Body mass index $\left(\mathrm{kg} / \mathrm{m}^{2}\right) ; \mathrm{n}(\%)$} \\
\hline$<18.5$ & $106(27.8)$ & $58(15.3)$ & $<0.001$ & $111(24.0)$ & $38(9.0)$ & $<0.001$ \\
\hline $18.5-24.99$ & $258(67.5)$ & $233(61.3)$ & & $314(67.8)$ & $228(53.9)$ & \\
\hline$\geq 25$ & $18(4.7)$ & $89(23.4)$ & & $38(8.2)$ & $157(37.1)$ & \\
\hline \multicolumn{7}{|l|}{ Educational level; n (\%) } \\
\hline Undergraduate or higher & $16(4.2)$ & $173(45.5)$ & $<0.001$ & $3(0.7)$ & $95(22.5)$ & $<0.001$ \\
\hline Up to 12 years of formal education & $51(13.4)$ & $83(21.8)$ & & $24(5.2)$ & $94(22.2)$ & \\
\hline Up to 10 years of formal education & $76(19.9)$ & $54(14.2)$ & & $42(9.1)$ & $56(13.2)$ & \\
\hline$<10$ years of formal education & $174(45.6)$ & $60(15.8)$ & & $143(30.9)$ & $94(22.2)$ & \\
\hline Illiterate & $65(17.0)$ & $10(2.6)$ & & $251(54.2)$ & $84(19.9)$ & \\
\hline Farmer; n (\%) & $357(93.7)$ & $59(15.5)$ & $<0.001$ & $441(95.7)$ & $81(19.2)$ & $<0.001$ \\
\hline Monthly household income $\left(\mathrm{Rs}^{*}\right)$; mean (SD) & $6173(8486)$ & $21782(19143)$ & $<0.001$ & $6452(8417)$ & $22977(22839)$ & $<0.001$ \\
\hline \multicolumn{7}{|l|}{ Smoking status; $n$ (\%) } \\
\hline Non-smoker & $210(55.0)$ & $247(65.0)$ & $<0.001$ & $299(64.6)$ & $385(91.0)$ & $<0.001$ \\
\hline Ex-smoker & $30(7.9)$ & $57(15.0)$ & & $51(11.0)$ & $23(5.4)$ & \\
\hline Current smoker & $142(37.2)$ & $76(20.0)$ & & $113(24.4)$ & $15(3.6)$ & \\
\hline \multicolumn{7}{|l|}{ Age started smoking (years); n (\%) } \\
\hline$<11$ & $28(16.3)$ & $10(7.5)$ & $<0.001$ & $46(28.0)$ & $8(21.1)$ & 0.792 \\
\hline $11-15$ & $47(27.3)$ & $8(6.0)$ & & $28(17.1)$ & $8(21.1)$ & \\
\hline $16-20$ & $50(29.1)$ & $53(39.8)$ & & $53(32.3)$ & $12(31.6)$ & \\
\hline$>20$ & $47(27.3)$ & $62(46.6)$ & & $37(22.6)$ & $10(26.3)$ & \\
\hline Environmental tobacco smoke exposure; n (\%) & $291(76.2)$ & $194(51.1)$ & $<0.001$ & $354(76.5)$ & $167(39.5)$ & $<0.001$ \\
\hline$\geq 10$ years of current fuel use; $n(\%)$ & $317(83.0)$ & $173(45.5)$ & $<0.001$ & $393(84.9)$ & $187(44.2)$ & $<0.001$ \\
\hline
\end{tabular}

*Nepalese Rupees (1 US\$ $\approx 100$ Rs). 
homes $(13.4 \pm 2.2$ vs. $2.0 \pm 2.0 \mathrm{ppm}, \mathrm{p}<0.001)$. The levels of $\mathrm{PM}_{2.5}$ and $\mathrm{CO}$ were much higher during cooking particularly in those houses where biomass was used as cooking fuel (Additional file 1: Figure S1).

In general symptom prevalence increased with age (Additional file 2: Table S1). Table 2 presents age-adjusted prevalence of breathlessness, wheeze, and chronic bronchitic symptoms. Dsypnoea (mMRC $\geq$ Grade 2 ) and wheezing (ever or on most days/nights) were more common among biomass users compared to those who used nonbiomass fuel ( $\mathrm{p}<0.001$ ), with age-adjusted prevalence of dyspnoea being 17.8\% (95\% CI 14.1, 21.5\%) among female and $12.0 \%(8.9,15.1 \%)$ among male biomass fuel users, compared to $7.6 \%(5.1,10.1 \%)$ and $2.5 \%(1.0,4.1 \%)$ among cleaner fuel users. Likewise, wheezy chest was approximately three times more likely to be reported by those using biomass fuel. On the other hand, male non-biomass users reported significantly more chronic phlegm (12.9\%; 95\% CI 9.6, 16.3\%) compared to biomass users (3.0\%; 1.4, $4.7 \%, \mathrm{p}<0.001)$. Such difference was not observed in females. When restricting to non-smokers, all symptom prevalence was lower, although not statistically different from the entire sample. Dyspnoea and wheeze were more prevalent among biomass users. In contrast the prevalence of chronic phlegm was higher in non-biomass users $(\mathrm{p}<0.001)$, both in males and in females $(\mathrm{p}=0.041)$.

Adjusting for potential confounders, those using biomass were associated with a significantly increased risk in breathlessness and wheeze. The increase in risk for dyspnoea was larger among men $(\mathrm{OR}=7.88$; $95 \%$ CI 2.84 , $21.88)$ than among women (3.90; $2.00,7.79)$, but the opposite was true for wheeze (Table 3 ). There was a negative association between biomass use and chronic phlegm prevalence, although this was significant only in men $(\mathrm{OR}=0.21 ; 95 \% \mathrm{CI} 0.09,0.47)$. The magnitude of risk estimate was smaller when other measures of indoor pollutants (24-h mean $\mathrm{PM}_{2.5}, \mathrm{PM}_{2.5}>2 \mathrm{SD}$ and $\mathrm{CO}$ ) were used. Whilst the level of $\mathrm{PM}_{2.5}$ was much lower outdoors compared to indoors, there was a positive relationship between outdoor $\mathrm{PM}_{2.5}$ and chronic phlegm in both sexes, although neither reached statistical significance. Restriction to non-smokers made no material changes in the risk estimates, with statistical significance disappeared in wheeze among males due to the reduction in power (data not shown).

There was an inverse association between $\mathrm{FEV}_{1}$ and dyspnoea, ever wheeze and chest illness in the last 12 months in women and with chronic phlegm in men after adjusting for height, age, education, BMI, income and smoking status (Additional file 3: Table S2).

\section{Discussion}

This study shows that the risk of reporting wheeze (ever and on most days and nights) and dyspnoea (mMRC scale $\geq 2$ ) were significantly higher among those exposed to biomass smoke, particularly in women. These respiratory symptoms were also positively associated with quantitative measures of $\mathrm{PM}_{2.5}$ greater than two standard deviation of the mean but

Table 2 Respiratory symptoms* in Nepalese adult men and women according to household fuel type

\begin{tabular}{|c|c|c|c|c|c|c|c|c|c|c|}
\hline & \multicolumn{5}{|c|}{ Men } & \multicolumn{5}{|c|}{ Women } \\
\hline & \multicolumn{2}{|r|}{ Biomass } & \multicolumn{2}{|c|}{ Non-biomass } & \multirow{3}{*}{ p } & \multicolumn{2}{|r|}{ Biomass } & \multicolumn{2}{|c|}{ Non-biomass } & \multirow{3}{*}{$\mathrm{p}$} \\
\hline & $\mathrm{n}$ & $\%(95 \% \mathrm{Cl})$ & $\mathrm{n}$ & $\%(95 \% \mathrm{Cl})$ & & $\mathrm{n}$ & $\%(95 \% \mathrm{Cl})$ & $\mathrm{n}$ & $\%(95 \% \mathrm{Cl})$ & \\
\hline & 382 & & 380 & & & 463 & & 423 & & \\
\hline mMRC scale $\geq$ Grade 2 & 48 & $12.0(8.9,15.1)$ & 9 & $2.5(1.0,4.1)$ & $<0.001$ & 86 & $17.8(14.1,21.5)$ & 30 & $7.6(5.1,10.1)$ & $<0.001$ \\
\hline \multicolumn{11}{|l|}{ Wheeze } \\
\hline Ever & 91 & $23.5(19.5,27.4)$ & 32 & $8.7(5.6,11.7)$ & $<0.001$ & 152 & $32.0(28.0,36.0)$ & 41 & $10.3(7.4,13.2)$ & $<0.001$ \\
\hline On most days/nights & 71 & $18.2(14.5,21.9)$ & 22 & $6.0(3.4,8.6)$ & $<0.001$ & 122 & $25.7(21.8,29.6)$ & 30 & $7.5(5.0,9.9)$ & $<0.001$ \\
\hline Chronic cough & 19 & $4.7(2.7,6.7)$ & 19 & $5.3(3.0,7.6)$ & 0.719 & 22 & $4.4(2.5,6.3)$ & 16 & $4.2(2.3,6.0)$ & 0.864 \\
\hline Chronic phlegm & 12 & $3.0(1.4,4.7)$ & 48 & $12.9(9.6,16.3)$ & $<0.001$ & 19 & $4.0(2.0,6.0)$ & 24 & $5.8(3.6,8.0)$ & 0.223 \\
\hline Chronic cough and phlegm & 9 & $2.2(0.8,3.7)$ & 13 & $3.6(1.6,5.6)$ & 0.292 & 13 & $2.6(1.2,4.1)$ & 9 & $2.3(0.9,3.7)$ & 0.753 \\
\hline Non-smokers only & 210 & & 247 & & & 299 & & 385 & & \\
\hline mMRC scale $\geq$ Grade 2 & 16 & $8.6(4.7,12.5)$ & 3 & $1.1(-0.1,2.3)$ & $<0.001$ & 37 & $13.8(9.8,17.9)$ & 20 & $4.7(2.7,6.8)$ & $<0.001$ \\
\hline \multicolumn{11}{|l|}{ Wheeze } \\
\hline Ever & 31 & $15.3(10.1,20.4)$ & 16 & $6.3(3.3,9.3)$ & 0.004 & 66 & $23.8(19.1,28.6)$ & 27 & $6.5(4.1,9.0)$ & $<0.001$ \\
\hline On most days/nights & 22 & $10.9(6.4,15.4)$ & 11 & $4.3(1.8,6.8)$ & 0.014 & 58 & $20.9(16.4,25.5)$ & 22 & $5.3(3.2,7.5)$ & $<0.001$ \\
\hline Chronic cough & 8 & $4.3(1.5,7.2)$ & 7 & $2.6(0.7,4.4)$ & 0.305 & 6 & $2.3(0.3,4.4)$ & 9 & $2.1(0.8,3.4)$ & 0.867 \\
\hline Chronic phlegm & 5 & $2.7(0.4,5.0)$ & 18 & $6.7(3.7,9.7)$ & 0.041 & 6 & $2.0(0.4,3.6)$ & 19 & $4.9(2.7,7.2)$ & 0.041 \\
\hline Chronic cough and phlegm & 5 & $2.8(0.4,5.2)$ & 3 & $1.1(-0.2,2.4)$ & 0.241 & 4 & $1.5(0.0,2.9)$ & 6 & $1.5(0.3,2.6)$ & 0.989 \\
\hline
\end{tabular}

*Adjusted for age. 
Table 3 Adjusted* odds ratios for respiratory symptoms and airflow obstruction according to exposure to particulate pollution

\begin{tabular}{|c|c|c|c|c|c|c|c|c|c|c|}
\hline & \multicolumn{2}{|c|}{ Biomass } & \multicolumn{2}{|c|}{ Indoor 24-h mean $\mathrm{PM}_{2.5}$} & \multicolumn{2}{|c|}{$\mathrm{PM}_{2.5}>2 \mathrm{SD}$ of $24-\mathrm{h}$ mean } & \multicolumn{2}{|c|}{ Outdoor 24-h mean $\mathrm{PM}_{2.5}$} & \multicolumn{2}{|c|}{ Indoor 24-h mean CO } \\
\hline & OR $(95 \% \mathrm{Cl})$ & $\mathrm{p}$ & $\mathrm{OR}^{\dagger}(95 \% \mathrm{Cl})$ & $p$ & $\mathrm{OR}^{+}(95 \% \mathrm{Cl})$ & $p$ & $\mathrm{OR}^{\dagger}(95 \% \mathrm{Cl})$ & $p$ & $\mathrm{OR}^{\dagger}(95 \% \mathrm{Cl})$ & $p$ \\
\hline \multicolumn{11}{|c|}{ Men } \\
\hline \multicolumn{11}{|l|}{ Breathlessness } \\
\hline mMRC scale $\geq$ Grade 2 & $7.88(2.84,21.88)$ & $<0.001$ & $3.10(1.53,6.31)$ & 0.002 & $2.67(1.50,4.78)$ & 0.001 & $1.24(0.16,9.63)$ & 0.837 & $8.33(0.74,93.27)$ & 0.085 \\
\hline \multicolumn{11}{|l|}{ Wheeze/whistling } \\
\hline Ever & $2.48(1.28,4.82)$ & 0.007 & $1.61(0.96,2.69)$ & 0.070 & $1.72(1.20,2.46)$ & 0.003 & $3.06(1.28,7.31)$ & 0.012 & $1.28(0.43,3.83)$ & 0.656 \\
\hline On most days and nights & $2.03(0.99,4.16)$ & 0.053 & $1.20(0.65,2.19)$ & 0.563 & $1.29(0.87,1.91)$ & 0.202 & $3.31(1.35,8.13)$ & 0.009 & $1.35(0.34,5.31)$ & 0.666 \\
\hline \multicolumn{11}{|l|}{ Cough/phlegm } \\
\hline Chronic cough & $0.87(0.28,2.69)$ & 0.803 & $1.45(0.68,3.12)$ & 0.339 & $1.28(0.78,2.09)$ & 0.331 & $9.68(0.59,159.2)$ & 0.112 & $0.73(0.12,4.52)$ & 0.739 \\
\hline Chronic phlegm & $0.21(0.09,0.47)$ & $<0.001$ & $0.69(0.36,1.33)$ & 0.268 & $0.66(0.43,1.01)$ & 0.055 & $2.68(0.83,8.67)$ & 0.100 & $0.56(0.13,2.41)$ & 0.432 \\
\hline Chronic bronchitis & $0.62(0.17,2.31)$ & 0.476 & $1.75(0.70,4.39)$ & 0.233 & $1.09(0.60,1.97)$ & 0.773 & $3.02(0.32,28.02)$ & 0.331 & Not estimable & - \\
\hline \multicolumn{11}{|l|}{ Airflow obstruction } \\
\hline $\mathrm{FEV}_{1} / \mathrm{FVC}<0.70$ & $1.94(1.05,3.59)$ & 0.035 & $0.81(0.46,1.45)$ & 0.480 & $1.24(0.83,1.86)$ & 0.297 & $2.24(0.57,8.83)$ & 0.248 & $1.54(0.46,5.19)$ & 0.488 \\
\hline $\mathrm{FEV}_{1} / \mathrm{FVC}<\mathrm{LLN}$ & $1.11(0.41,3.00)$ & 0.840 & $0.86(0.30,2.45)$ & 0.778 & $1.08(0.55,2.12)$ & 0.818 & $2.15(0.17,27.33)$ & 0.554 & $0.41(0.20,5.12)$ & 0.557 \\
\hline \multicolumn{11}{|c|}{ Women } \\
\hline \multicolumn{11}{|l|}{ Breathlessness } \\
\hline mMRC scale $\geq$ Grade 2 & $3.90(2.00,7.79)$ & $<0.001$ & $1.37(0.74,2.53)$ & 0.313 & $1.80(1.19,2.74)$ & 0.005 & $3.13(1.17,8.32)$ & 0.022 & $0.95(0.36,2.56)$ & 0.924 \\
\hline \multicolumn{11}{|l|}{ Wheeze/whistling } \\
\hline Ever & $4.62(2.71,7.87)$ & $<0.001$ & $1.73(1.13,2.66)$ & 0.012 & $1.73(1.25,2.39)$ & 0.001 & $1.38(0.57,3.37)$ & 0.478 & $2.36(0.95,5.81)$ & 0.063 \\
\hline On most days and nights & $3.55(2.06,6.13)$ & $<0.001$ & $1.53(0.93,2.51)$ & 0.095 & $1.58(1.10,2.27)$ & 0.014 & $1.41(0.52,3.80)$ & 0.501 & $3.31(1.01,10.80)$ & 0.048 \\
\hline \multicolumn{11}{|l|}{ Cough/phlegm } \\
\hline Chronic cough & $0.41(0.15,1.18)$ & 0.098 & $0.41(0.18,0.92)$ & 0.031 & $0.48(0.26,0.91)$ & 0.024 & $0.56(0.13,2.46)$ & 0.442 & $0.10(0.01,0.65)$ & 0.016 \\
\hline Chronic phlegm & $0.42(0.15,1.20)$ & 0.106 & $0.81(0.35,1.86)$ & 0.612 & $0.62(0.31,1.22)$ & 0.165 & $1.63(0.31,8.60)$ & 0.562 & $0.23(0.06,0.95)$ & 0.042 \\
\hline Chronic bronchitis & $0.30(0.08,1.11)$ & 0.071 & $0.39(0.12,1.30)$ & 0.125 & $0.35(0.14,0.85)$ & 0.021 & $0.51(0.06,4.45)$ & 0.541 & $0.04(0.003,0.58)$ & 0.018 \\
\hline \multicolumn{11}{|l|}{ Airflow obstruction } \\
\hline $\mathrm{FEV}_{1} / \mathrm{FVC}<0.70$ & $1.30(0.67,2.54)$ & 0.436 & $0.94(0.53,1.67)$ & 0.844 & $0.90(0.57,1.41)$ & 0.647 & $1.54(0.54,4.36)$ & 0.419 & $2.44(0.70,8.44)$ & 0.160 \\
\hline $\mathrm{FEV}_{1} / \mathrm{FVC}<\mathrm{LLN}$ & $1.67(0.66,4.23)$ & 0.281 & $1.26(0.62,2.58)$ & 0.527 & $1.45(0.77,2.74)$ & 0.254 & $0.88(0.19,4.06)$ & 0.873 & $2.00(0.29,13.69)$ & 0.479 \\
\hline
\end{tabular}

*Adjustments for age, sex, educational level, income, BMl, smoking status.

$\mathrm{O}$ OR for 10 -fold increase in pollutant level. 
not to the 24-h average mean, suggesting that peaks of pollution may be more important than average exposures. Those exposed to biomass smoke who had respiratory symptoms were more likely to have lower lung function and the prevalence of airflow obstruction was significantly higher amongst the older individuals.

All respiratory symptoms were self-reported without further clinical assessment, which may have resulted in misclassification. People in low-income countries often consider wheeze, breathlessness and bringing up phlegm to some extent as normal which may result in under-reporting of symptoms and if this was differentially expressed between exposed and non-exposed groups this may underestimate the true risk. The respiratory questionnaire used was developed and validated in developed countries and although our version was back translated to ensure best delivery of questions interpretative issues may have arisen. For instance, there is no terminology in Nepali for the term "wheeze" which could have caused some confusion among interviewees but efforts were made to minimise these by using bilingual speakers from their local communities trained in questionnaire delivery.

The major strengths of this study are its size, the use of a comparator group (studying biomass smoke exposed and non-exposed groups) and the adjustment for confounders, often inadequately dealt with in previous studies. We included young adults ( $\geq 16$ years) because in Nepal cooking is usually delegated to adolescents, particularly girls and those living in the rural areas.

Previous work has studied populations using different types of biomass smoke for varying lengths of time making comparisons difficult especially when the issues of confounding is inconsistently addressed. Behera and Jindal [11] reported prevalences of respiratory symptoms for different types of fuel users (biomass, kerosene, LPG and mixed) in Indian women and found that respiratory symptoms did not follow any clear pattern: chronic bronchitis was greater in biomass users, cough greater in kerosene users and breathlessness in mixed fuel users. Other studies [12,13] have not found an association between exposures to wood smoke and respiratory symptoms but a randomised controlled trial study in Guatemala [14] of respiratory symptoms in women involved in cooking reported that women provided with improved cook stoves reported significantly less wheeze compared to baseline but with no significant reduction in other respiratory symptoms.

Our study recorded significantly higher "ever wheeze" in the rural compared to the urban area, similar to previous reports from Nepal (wood smoke) [6,15], Canada [16,17] (smoke from burning agricultural residue and wood), India [11] (biomass smoke), China [18,19] (coal smoke) and Guatemala [20] (wood smoke). The presence of significantly higher prevalence of wheeze (ever, on most days/nights, and in the last 12 months) in the rural, life- long non-smoking population further suggests that the risk of being wheezy is likely to increase in populations exposed to biomass smoke. The risk of ever wheeze in biomass smoke exposed women was $60 \%$ higher compared to men but there were no significant differences between urban males and females. The risk of ever wheeziness increased with age for the biomass exposed population but not for the non-exposed population suggesting that prolonged exposure to biomass smoke increases the risk although in other studies respiratory symptoms have generally increased with age. Ex-smokers showed more than a six-fold increase in ever wheeze in the biomass smoke exposed population and a three-fold increase in the urban population compared to life-long non-smokers whereas the additional risks in current smokers were nearly three and two fold respectively. The higher risk in the ex-smokers could be explained as the ex-smokers gave up smoking only after they were medically diagnosed with respiratory problems which might have persuaded them to quit smoking. Similar results for ex- and current smokers were found for wheeze in the last 12 months.

Self-reported chronic phlegm was significantly higher in non-smoking, non-biomass exposed men (6.7\%) and women $(4.9 \%)$ compared to the exposed group (men $2.7 \%$, women $2.0 \%$ ), contrary to the findings reported by other studies in Nepal [6] and other countries [11,19]. This finding is both marked and surprising and while this might be due to bias in reporting, the risk in the urban population might be real. Most of the urban dwellers were exposed to biomass at some point in their early years and there might have been a residual effect of that early pollutant exposure but this should not overwhelm current exposure. This finding could also possibly be due to the higher urban outdoor air pollution concentrations from vehicle generated pollutants although other causes unrelated to air quality such as post nasal discharge may be a possibility. There have been abundant studies in industrialised countries on the short and long term health effects of vehicle generated ambient air pollution, with special emphasis on respiratory and cardiovascular health effects [21-23] showing positive correlations between these health outcomes and concentrations of ambient air pollutants. It is possible that vehicle generated particles released in ambient air are more toxic in the context of mucus hyper-secretion compared to biomass smoke and thus cause more respiratory symptoms but future studies are needed to assess the differential toxicity due to different types of fuel $[24,25]$ and also compare with existing toxicity data from vehicle generated particles.

Unsurprisingly production of cough and phlegm was more common in both current and ex-smokers and also in older age groups. Phlegm production was greatest in the biomass exposed illiterate population indicating that socio-economic status is a risk factor and living within a 
kitchen with no ventilation increased phlegm production in both the rural and urban populations but not statistically significantly so. This indicates that exposure to kitchen fumes (smoke from fuel burning and also mist from cooking oil when heated) might be a risk factor, again a potential surrogate indicator of exposure.

Biomass smoke exposed men and women reported more breathlessness compared to their non-exposed counterparts but the difference was only significant for biomass smoked compared to non-biomass exposed males. Recorded breathlessness in this study is lower compared to other published studies. As the biomass smoke exposed area was in a hilly region, the population might have attributed breathlessness to exertion rather than to inhalation of biomass smoke, especially as females do a lot of manual work in the fields. It is also possible that our sample is relatively young (mean age 35 years), hence less likely to have (and admit to have) dyspnoea. Cooking with kerosene increased the risk of developing breathlessness in urban dwellers (results not shown) but this result was based on a very small number of individuals and could just be a chance finding.

Direct measurement of exposure as mean 24-h indoor $\mathrm{PM}_{2.5}$ in this study failed to show any significant associations with respiratory symptoms but some of the proxy measurements such as use of biomass, illiteracy and poor ventilation (data not shown) showed a relationship suggesting that exposure to biomass smoke might be a risk for respiratory symptoms. Of interest is that when we considered peak smoke exposures (taken as mean $\mathrm{PM}_{2.5}>2$ SDs above the 24-h mean) a relationship between respiratory symptoms and exposures emerged, suggesting that time spent at concentrations that are considerably higher than background may be more important than consistently high exposures.

The odds of presence of airflow obstruction was greater amongst those exposed to biomass although it did not reach statistical significance. The higher prevalence of respiratory symptoms such as wheeze and breathlessness without having airflow obstruction could be due to the high proportion of younger individuals in our sample. Alternatively, it is possible that spirometry was not sensitive enough to detect the very early stage of airflow obstruction.

\section{Conclusions}

In summary, in this study the prevalence of wheeze in a biomass smoke exposed population is in line with most of the previous findings in Nepal and other low-income countries but the results for cough differ. This ambiguity regarding the cough and phlegm results from urban Nepal should be interpreted with special attention. Future studies in urban Nepal looking at respiratory symptoms should be looking at all the aspects like toxicity of outdoor pollutants and whether any other risk factors are confounding the results.

\section{Additional files}

Additional file 1: Figure S1. Typical temporal profiles of $\mathrm{PM}_{2.5}$ and $\mathrm{CO}$ concentrations.

Additional file 2: Table S1. Respiratory symptoms in Nepalese adult men and women according to household fuel type, stratifying for age in tertiles.

Additional file 3: Table S2. Regression coefficients of lung function indices using robust variance estimates.

\section{Abbreviations}

BMI: Body mass index; Cl: Confidence interval; CO: Carbon monoxide; COPD: Chronic obstructive pulmonary disease; ECRHS: European community respiratory health survey; FEV $\mathrm{F}_{1}$ : Forced expiratory volume in 1 second; FVC: Forced vital capacity; LLN: Lower limit of normal; LPG: Liquefied petroleum gas; MRC: Medical Research Council; OR: Odds ratio; PM: Particulate matter; SD: Standard deviation; VDC: Village development community.

\section{Competing interests}

The authors declare that they have no competing interests.

\section{Authors' contributions}

OK is the guarantor of the paper, taking responsibility for the integrity of the work as a whole, from inception to published articles. OK, SSemple, PS, WCS and JA conceived and designed the study, interpreted results, and contributed to authorship of the manuscript. OK, GSD, MS, KBHL and SSadhra processed the data, contributed to the analysis plan and editing the manuscript. SG helped in the data entry, cleaning and editing the manuscript. All authors read and approved the final manuscript.

\section{Acknowledgements}

We would like to thank all the participants for taking part in this study. We are extremely grateful to the local research staff (Kundan Kumar Jha, Naniram Timalsina, Anita Dhungana, Bishnumaya Adhikar, Indra Kumar Bohara, Bhola Dhungana, Pratichha Dali and Rajeev Shrestha) for their help in sampling and Krishna Kunwar, Lava Dhungana, Pradip Raj Dali and Bigyan Kafle for their help in the selection of the sampling locations and co-ordinating with the house members. We are also grateful to George Henderson for his help with arranging the sampling equipment.

\section{Author details}

${ }^{1}$ Clinical Trials Service Unit \& Epidemiological Studies Unit, Nuffield Department of Population Health, University of Oxford, Oxford OX3 7LF, UK. ${ }^{2}$ Scottish Centre for Indoor Air, Division of Applied Health Sciences, School of Medicine, University of Aberdeen, Aberdeen AB24 3FX, UK. ${ }^{3}$ Department of Child Health, Royal Aberdeen Children's Hospital, University of Aberdeen, Aberdeen AB25 2ZG, UK. ${ }^{4}$ Institute of Occupational and Environmental Medicine, University of Birmingham, Birmingham B15 2TT, UK. ${ }^{5}$ School of Health and Related Research, University of Sheffield, Sheffield S10 2TN, UK. ${ }^{6} \mathrm{~S}$ chool of Medicine and Dentistry, University of Aberdeen, Aberdeen AB24 3FX, UK.

Received: 18 June 2014 Accepted: 28 October 2014

Published: 6 November 2014

\section{References}

1. Naeher LP, Brauer M, Lipsett M, Zelikoff JT, Simpson CD, Koenig JQ, Smith KR: Woodsmoke health effects: a review. Inhal Toxicol 2007, 19:67-106.

2. Kurmi OP, Lam KB, Ayres JG: Indoor air pollution and the lung in low- and medium-income countries. Eur Respir J 2012, 40:239-254.

3. Kurmi OP, Semple S, Simkhada P, Smith WC, Ayres JG: COPD and chronic bronchitis risk of indoor air pollution from solid fuel: a systematic review and meta-analysis. Thorax 2010, 65:221-228.

4. Bruce N, Neufeld L, Boy E, West C: Indoor biofuel air pollution and respiratory health: the role of confounding factors among women in highland Guatemala. Int J Epidemiol 1998, 27:454-458.

5. Zhong N, Wang C, Yao W, Chen P, Kang J, Huang S, Chen B, Wang C, Ni D, Zhou Y, Liu S, Wang X, Wang D, Lu J, Zheng J, Ran P: Prevalence of 
chronic obstructive pulmonary disease in China: a large, populationbased survey. Am J Respir Crit Care Med 2007, 176:753-760.

6. Shrestha IL, Shrestha SL: Indoor air pollution from biomass fuels and respiratory health of the exposed population in Nepalese households. Int J Occup Environ Health 2005, 11:150-160.

7. Kurmi OP, Devereux GS, Smith WC, Semple S, Steiner MF, Simkhada P, Lam $\mathrm{KB}$, Ayres JG: Reduced lung function due to biomass smoke exposure in young adults in rural Nepal. Eur Respir J 2013, 41:25-30.

8. Kurmi OP, Semple S, Steiner M, Henderson GD, Ayres JG: Particulate matter exposure during domestic work in Nepal. Ann Occup Hyg 2008, 52:509-517.

9. Mahler DA, Wells CK: Evaluation of clinical methods for rating dyspnea. Chest 1988, 93:580-586.

10. World Health Organization: Physical status: The use and interpretation of anthropometry. Report of a WHO Expert Committee. Technical Report Series No. 854. Geneva: WHO; 1995.

11. Behera D, Jindal SK: Respiratory symptoms in Indian women using domestic cooking fuels. Chest 1991, 100:385-388.

12. Maier WC, Arrighi HM, Morray B, Llewellyn C, Redding GJ: Indoor risk factors for asthma and wheezing among Seattle school children. Environ Health Perspect 1997, 105:208-214.

13. Ellegard A: Cooking fuel smoke and respiratory symptoms among women in low-income areas in Maputo. Environ Health Perspect 1996, 104:980-985.

14. Smith-Sivertsen T, Diaz E, Pope D, Lie RT, Diaz A, McCracken J, Bakke P, Arana B, Smith KR, Bruce N: Effect of reducing indoor air pollution on women's respiratory symptoms and lung function: The RESPIRE Randomized Trial, Guatemala. Am J Epidemiol 2009, 170:211-220.

15. Pandey MR: Domestic smoke pollution and chronic bronchitis in a rural community of the Hill Region of Nepal. Thorax 1984, 39:337-339.

16. Long WQ, Tate RB, Neuman M, Manfreda J, Becker AB, Anthonisen NR: Respiratory symptoms in a susceptible population due to burning of agricultural residue. Chest 1998, 113:351-357.

17. Guggisberg M, Hessel PA, Michaelchuk D, Ahmed I: Respiratory symptoms and exposure to wood smoke in an isolated northern community. Can J Public Health 2003, 94:372-376.

18. Zhang LX, Enarson DA, He GX, Li B, Chan-Yeung M: Occupational and environmental risk factors for respiratory symptoms in rural Beijing, China. Eur Respir J 2002, 20:1525-1231.

19. Salo PM, Xia J, Johnson CA, Li Y, Kissling GE, Avol EL, Liu C, London SJ: Respiratory symptoms in relation to residential coal burning and environmental tobacco smoke among early adolescents in Wuhan, China: a cross-sectional study. Environ Health 2004, 3:14.

20. Diaz E, Bruce N, Pope D, Lie RT, Diaz A, Arana B, Smith KR, Smith-Sivertsen T: Lung function and symptoms among indigenous Mayan women exposed to high levels of indoor air pollution. Int J Tuberc Lung Dis 2007, 11:1372-1379

21. Frew AJ, Salvi SS: Diesel exhaust particles and respiratory allergy. Clin Exp Allergy 1997, 27:237-239.

22. Brunekreef B, Holgate ST: Air pollution and health. Lancet 2002, 360:1233-1242.

23. van Vliet P, Knape M, de Hartog J, Janssen N, Harssema H, Brunekreef B: Motor vehicle exhaust and chronic respiratory symptoms in children living near freeways. Environ Res 1997, 74:122-132.

24. Kurmi OP, Dunster C, Ayres JG, Kelly FJ: Oxidative potential of smoke from burning wood and mixed biomass fuels. Free Radic Res 2013, 47:829-835.

25. Mudway I, Duggan S, Venkataraman C, Habib G, Kelly F, Grigg J: Combustion of dried animal dung as biofuel results in the generation of highly redox active fine particulates. Part Fibre Toxicol 2005, 2:6.

doi:10.1186/1476-069X-13-92

Cite this article as: Kurmi et al.: The effect of exposure to biomass smoke on respiratory symptoms in adult rural and urban Nepalese populations. Environmental Health 2014 13:92.

\section{Submit your next manuscript to BioMed Central and take full advantage of:}

- Convenient online submission

- Thorough peer review

- No space constraints or color figure charges

- Immediate publication on acceptance

- Inclusion in PubMed, CAS, Scopus and Google Scholar

- Research which is freely available for redistribution

Submit your manuscript at www.biomedcentral.com/submit
Biomed Central 